\title{
Evaluating active roles of community health workers in accelerating universal access to health services for malaria in Palawan, the Philippines
}

Emilie Louise Akiko Matsumoto-Takahashi and Shigeyuki Kano*

\begin{abstract}
Background: Palawan is the most malaria-endemic province in the Philippines. In an effort to confront malaria in areas with limited healthcare facilities, microscopists (community health workers) have been trained to diagnose malaria since 1999.

Methods: We reviewed the epidemiological data and related literature which analyzed the achievements of the microscopists and their tasks in order to propose a strategy to strengthen community-based malaria control.

Results: The epidemiological data showed that there had been a drastic decrease in malaria morbidity and mortality throughout the province following the launch of the strategy. Microscopists clearly enhanced the feasibility of early diagnosis and treatment throughout the province. However, it remained necessary to implement anti-malarial measures focusing on children under 5 years of age who live in the southern region of the province. The analysis of our published papers also enabled us to propose a new strategy to enhance activities by microscopists to raise malaria awareness in their respective communities.

Conclusions: These low-cost activities are expected to strengthen the preventive measures implemented by the residents and to drive more people to seek appropriate treatment. Consequently, this new strategy could accelerate the efforts to eliminate malaria in the province of Palawan that will be adopted in the WHO's Global Technical Strategy for Malaria 2016-2030, in order to achieve the Sustainable Development Goals by 2030.
\end{abstract}

Keywords: Universal health access, Malaria, Community health workers, Microscopist, Palawan, The Philippines

\section{Background}

Malaria is one of the most important parasitic infections in humans. In 2013, it accounted for approximately 584,000 deaths (range 367,000-755,000) worldwide [1]. Although malaria was once prevalent throughout much of the inhabited world, it has been eliminated in roughly half of the world's countries and now is mostly restricted to rural tropical regions [2]. From 2000 to 2013, the number of malaria infections dropped by $26 \%$ from 173 million to 128 million, while the worldwide mortality

\footnotetext{
* Correspondence: kano@ri.ncgm.go.jp

Department of Tropical Medicine and Malaria, Research Institute, National

Center for Global Health and Medicine, 1-21-1 Toyama, Shinjuku-ku, Tokyo 162-8655, Japan
}

(c) 2016 Matsumoto-Takahashi and Kano. Open Access This article is distributed under the terms of the Creative Commons Attribution 4.0 International License (http://creativecommons.org/licenses/by/4.0/), which permits unrestricted use, distribution, and reproduction in any medium, provided you give appropriate credit to the original author(s) and the source, provide a link to the Creative Commons license, and indicate if changes were made. The Creative Commons Public Domain Dedication waiver (http://creativecommons.org/publicdomain/zero/1.0/) applies to the data made available in this article, unless otherwise stated.

rate decreased by $47 \%$ [1]. This decrease occurred as a result of substantial increases in donor funding, improved control, and increased enthusiasm for malaria elimination $[3,4]$.

Improving the availability of effective health services has been an essential strategy for malaria elimination in all of the endemic regions [1]. At present, malaria mostly remains in remote and rural regions where essential preventive measures are delivered to the populations that need them the most by poor health systems with insufficient human resources $[5,6]$. Thus, the targeting of residents in these areas, including socially vulnerable groups such as ethnic minorities and migrants, is a key to malaria control $[7,8]$. 
To overcome these challenges in many malaria-endemic regions, the validity and usefulness of strategies that utilize community health workers (CHWs) has been proposed $[9,10]$. According to the World Health Organization (WHO), CHWs should meet the following criteria: be members of the communities where they work; be selected by the communities; be answerable to the communities for their activities; be supported by health systems, but not necessarily a part of their organization; and have shorter training than professional workers [11]. In rural areas, where there is a recognized paucity of human capacity and health systems, the utilization of CHWs is a potentially inexpensive, effective, and sustainable approach for bringing malaria diagnosis and treatment closer to households [11].

Although CHWs, such as barangay health workers (BHWs) or government-trained health volunteers, have been operating in rural villages in the Philippines since 1981, their involvement in malaria control has not been satisfactory [12]. This has largely been due to inadequate training, insufficient logistical support, poorly sustained motivational schemes, and a lack of community support.

With this background, a community-based malaria control program was established in Palawan, one of the most malaria-endemic provinces in the Philippines, in 1999 [13-16]. The program, which was called Kilusan Ligtas Malaria (KLM) (Tagalog: Movement Against Malaria), involved training $344 \mathrm{CHWs}$ as malaria microscopists (one microscopist per malaria-endemic village). The microscopists diagnose malaria in febrile patients via microscopy and prescribe first-line anti-malarial drugs to malaria- infected patients. Microscopists also implement community awareness-raising activities that are aimed at preventing the transmission of malaria among their patients and their patients' families. Since this program started, diagnostic techniques that allow for the early diagnosis of malaria have been extended to the entire province. This communitybased malaria control program was partly maintained with the aid of the Japan International Cooperation Agency and the ongoing Global Fund Project through the Pilipinas Shell Foundation, Inc.

To accelerate the efforts to eliminate malaria in Palawan, this community-based malaria control program must be evaluated. The present study also aimed to find out the value of the capacity for microscopy and active roles of CHWs by reviewing the epidemiological data in Palawan and the related literature. The findings may also be used to enhance the performance of CHWs in other settings.

\section{Methods \\ Study area}

Palawan is the most malaria-endemic province in the Philippines. Eighteen out of the 23 legislated municipalities and the capital city of Puerto Princesa are considered to be malarious [13-16]. The capital city is located in the center of this oblong island province and divides the island into the northern and southern regions. The island is mostly covered by tropical rainforests, which limit the residents' access to affordable healthcare facilities. In 2010, the population of Palawan was $1,025,800$. The residents lived in 367 villages in 23 municipalities [17]. The ethnicities of the residents include Tagalog (the

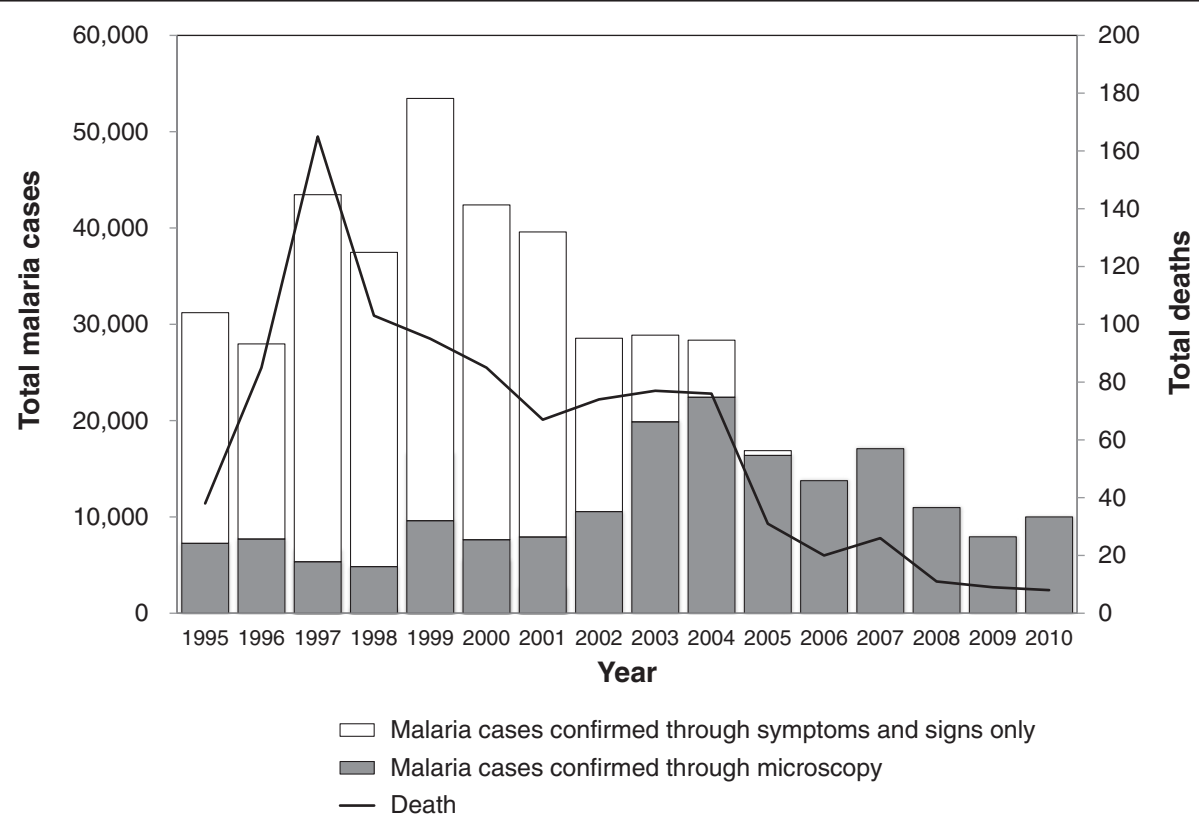

Fig. 1 The malaria trends in Palawan. The figure was created by the authors based on the data of the Provincial Health Report, 1995-2010 [13-16] 
predominant ethnic group in the Philippines), Cuyunon, Hiligaynon, Palawan, Cebuano, Ilocano, Bisaya, Kagayanan, and Tagbanwa.

\section{Data collection}

We reviewed the epidemiological data and related literature which analyzed the achievements of the microscopists and their tasks. Available epidemiological data of malaria morbidity and mortality in Palawan were collected in the Provincial Health Office of Palawan and KLM main office in Puerto Princesa City, Palawan, the Philippines. Besides, we searched and reviewed related articles in PubMed which had been published since the earliest date up to December 2015.

\section{Results}

\section{Malaria in the Philippines}

Malaria has existed in the Philippines for centuries, and several malaria control strategies have been implemented [18-20]. When the Spanish arrived and started to occupy the Philippines in the 16th century, the country was largely covered with extensive forests, which the local people avoided due to the risk of infection [18]. Forest exploitation using forced local labor contributed to several malaria epidemics and the persistence of malaria within the Philippines. After the Spanish-American War in 1898, the United States occupied the Philippines and programs were implemented to minimize the spread of several diseases including malaria, cholera, smallpox, dysentery, and tuberculosis. In 1931, there were approximately 20,000 deaths due to malaria per year and the strategy for malaria control was to examine blood smears by microscope, to treat cases with quinine alone or with plasmochin, and to use screens and bed nets [19]. The start of World War II saw an increase in malaria morbidity and mortality throughout the Philippines.

After the end of World War II, malaria-vector control was achieved by dichloro-diphenyl-trichloroethane (DDT) spraying in the province of Mindanao, an island in the southeast of the Philippines $[18,20]$. DDT spraying proved effective, and the spraying program was expanded to cover

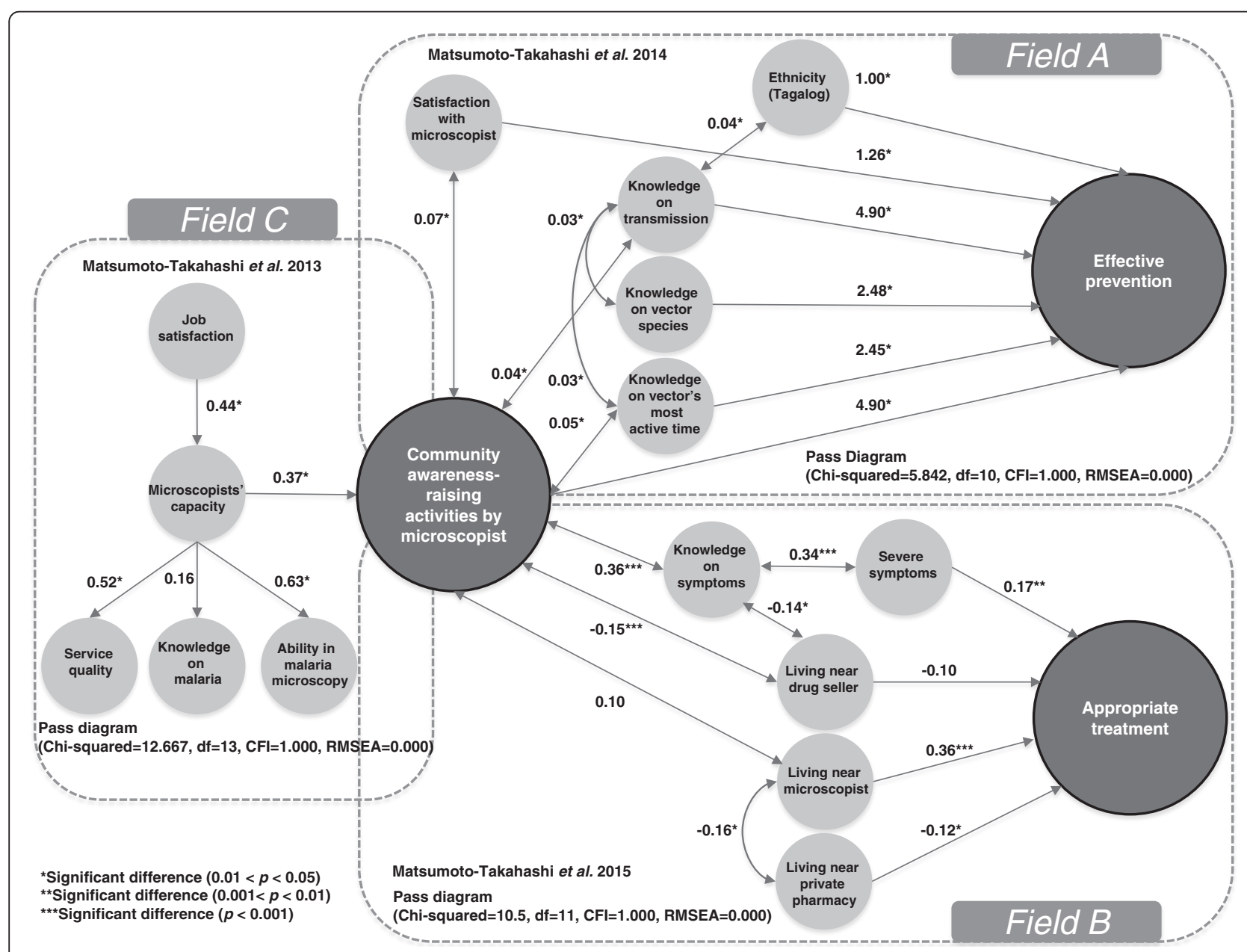

Fig. 2 The determinants of community awareness-raising activities by microscopists, appropriate treatment, and effective prevention 
Table 1 Trends in the leading causes of morbidity in Palawan from 2005 to 2009

\begin{tabular}{|c|c|c|c|c|c|c|c|c|c|c|c|c|c|c|c|}
\hline \multirow[t]{2}{*}{ Causes of morbidity } & \multicolumn{3}{|l|}{2005} & \multicolumn{3}{|l|}{2006} & \multicolumn{3}{|l|}{2007} & \multicolumn{3}{|l|}{2008} & \multicolumn{3}{|l|}{2009} \\
\hline & $\begin{array}{l}\text { Top } \\
10\end{array}$ & Number & Rate $^{a}$ & $\begin{array}{l}\text { Top } \\
10\end{array}$ & Number & Rate $^{a}$ & $\begin{array}{l}\text { Top } \\
10\end{array}$ & Number & Rate $^{a}$ & $\begin{array}{l}\text { Top } \\
10\end{array}$ & Number & Rate $^{a}$ & $\begin{array}{l}\text { Top } \\
10\end{array}$ & Number & Rate $^{a}$ \\
\hline URTI/ARI & $1 \mathrm{st}$ & 28,011 & 4303 & $1 s t$ & 27,959 & 4201 & $1 \mathrm{st}$ & 19,217 & 2392 & $1 s t$ & 24,030 & 3457 & $1 \mathrm{st}$ & 38,857 & 4964 \\
\hline Influenza & 2nd & 17,085 & 2625 & 2nd & 16,091 & 2418 & 2nd & 16,266 & 1477 & 2nd & 16,719 & 2405 & 2nd & 13,528 & 1728 \\
\hline Malaria $^{\mathrm{b}}$ & $3 r d$ & 10,334 & 1588 & $3 r d$ & 12,640 & 1899 & $3 r d$ & 10,048 & 973 & 5 th & 5865 & 844 & 4 th & 6558 & 838 \\
\hline Diarrhea & 4th & 7038 & 1081 & 4th & 8932 & 1342 & 4th & 6617 & 831 & 4 th & 7061 & 1016 & 7th & 3655 & 467 \\
\hline Bronchitis & 5 th & 4800 & 737 & 5 th & 7908 & 1188 & 6 th & 4382 & 521 & $3 r d$ & 8303 & 1195 & 6th & 3738 & 477 \\
\hline Hypertension & 6th & 3317 & 510 & 6th & 4843 & 728 & 7th & 3540 & 502 & 7th & 3000 & 432 & $3 r d$ & 7335 & 937 \\
\hline Urinary tract infection & 7th & 2700 & 415 & 7th & 2856 & 429 & 8th & 3417 & 185 & 6th & 5671 & 816 & 5 th & 4483 & 573 \\
\hline Pneumonia & 8th & 2260 & 347 & 8th & 1470 & 221 & 5 th & 5652 & 644 & 8th & 2994 & 431 & 10th & 2471 & 316 \\
\hline Anemia & 9th & 1447 & 222 & 10th & 858 & 129 & & & & & & & & & \\
\hline $\begin{array}{l}\text { Pulmonary } \\
\text { tuberculosis }\end{array}$ & 10th & 1029 & 158 & 9th & 949 & 143 & 10th & 971 & 127 & & & & & & \\
\hline Skin disease & & & & & & & 9th & 1261 & 143 & & & & & & \\
\hline Gastritis & & & & & & & & & & 9th & 1402 & 202 & 9th & 2066 & 264 \\
\hline $\begin{array}{l}\text { Accident/wound/ } \\
\text { injury }\end{array}$ & & & & & & & & & & 10th & 1130 & 163 & 8th & 2834 & 362 \\
\hline
\end{tabular}

The table was created by the author based on the annual provincial health report of the province of Palawan [15, 16]

Abbreviations: URTI upper respiratory tract infection, $A R I$ acute respiratory infection

${ }^{\text {a }}$ Rate per 100,000 population

${ }^{\mathrm{b}}$ The number does not match that in Table 1 due to differences in the methods of data collection (the data for this table was only collected in provincial and private hospitals)

Table 2 Trends in the leading causes of mortality in Palawan from 2005 to 2009

\begin{tabular}{|c|c|c|c|c|c|c|c|c|c|c|c|c|c|c|c|}
\hline \multirow[t]{2}{*}{ Causes of mortality } & \multicolumn{3}{|l|}{2005} & \multicolumn{3}{|l|}{2006} & \multicolumn{3}{|l|}{2007} & \multicolumn{3}{|l|}{2008} & \multicolumn{3}{|l|}{2009} \\
\hline & $\begin{array}{l}\text { Top } \\
10\end{array}$ & Number & $\overline{\text { Rate }^{a}}$ & $\begin{array}{l}\text { Top } \\
10\end{array}$ & Number & Rate $^{a}$ & $\begin{array}{l}\text { Top } \\
10\end{array}$ & Number & Rate $^{a}$ & $\begin{array}{l}\text { Top } \\
10\end{array}$ & Number & Rate $^{a}$ & $\begin{array}{l}\text { Top } \\
10\end{array}$ & Number & Rate $^{a}$ \\
\hline Pneumonia & $1 s t$ & 239 & 37.0 & $1 s t$ & 224 & 33.7 & $1 \mathrm{st}$ & 313 & 46.0 & $1 s t$ & 285 & 41.0 & 1 st & 337 & 43.1 \\
\hline Hypertension & 2nd & 155 & 24.0 & 5 th & 101 & 15.2 & 7th & 78 & 11.5 & & & & 4 th & 108 & 13.8 \\
\hline Pulmonary tuberculosis & $3 r d$ & 128 & 20.0 & $3 r d$ & 122 & 18.3 & 4 th & 163 & 24.0 & 4th & 97 & 14.0 & 6th & 99 & 12.7 \\
\hline $\begin{array}{l}\text { Unspecified natural } \\
\text { cause }\end{array}$ & 4th & 123 & 19.0 & 9th & 60 & 9.0 & $3 r d$ & 181 & 26.7 & 10th & 57 & 8.2 & & & \\
\hline Cancer & 5 th & 105 & 16.0 & 4th & 105 & 15.7 & 5 th & 137 & 20.1 & 2nd & 107 & 15.4 & 2nd & 123 & 15.8 \\
\hline Diarrhea & 6th & 95 & 15.0 & 8th & 63 & 9.5 & 6th & 125 & 18.4 & & & & 8th & 72 & 9.2 \\
\hline Myocardial infarction & 7th & 83 & 13.0 & 2nd & 147 & 22.1 & & & & 8th & 59 & 8.5 & & & \\
\hline Accident/wound/injury & 8th & 67 & 10.0 & & & & & & & & & & & & \\
\hline Stillbirth & 9th & 56 & 9.0 & & & & & & & 6th & 63 & 9.1 & & & \\
\hline Myocarditis & 10th & 54 & 8.0 & & & & 8th & 76 & 11.2 & 9th & 59 & 8.5 & 9th & 69 & 8.8 \\
\hline Congestive heart failure & & & & 6th & 87 & 13.1 & & & & & & & & & \\
\hline Renal failure & & & & 7 th & 80 & 12.0 & 9th & 72 & 10.6 & 7th & 63 & 9.1 & 7th & 77 & 9.8 \\
\hline Peptic ulcer & & & & & & & 10th & 54 & 8.0 & & & & & & \\
\hline Cardiovascular disease & & & & & & & 2nd & 295 & 43.4 & $3 r d$ & 103 & 14.9 & 5th & 101 & 12.9 \\
\hline Cerebrovascular accident & & & & & & & & & & 5 th & 85 & 12.2 & $3 r d$ & 111 & 14.2 \\
\hline Diabetes mellitus & & & & & & & & & & & & & 10th & 64 & 8.2 \\
\hline
\end{tabular}

The table was created by the author based on the annual provincial health report of the province of Palawan $[15,16]$

a Rate per 100,000 population 
Table 3 The population distribution and malaria incidence per region (2009)

\begin{tabular}{llllllcrc}
\hline Region & Population & Smear & Confirmed malaria cases & P. falciparum & $<^{\text {a }}$ (\%) & ABER & SPR & API \\
\hline Total & 872,390 & 89,290 & 7606 & $73.1 \%$ & 17.3 & 10.3 & 8.52 & 8.72 \\
Northern region & 334,392 & 23,626 & 488 & $66.0 \%$ & 11.1 & 7.07 & 2.07 & 1.46 \\
Puerto Princesa City & 207,119 & 8776 & 880 & $63.5 \%$ & 8.4 & 4.24 & 10.0 & 4.25 \\
Southern region & 330,879 & 56,888 & 6238 & $75.0 \%$ & 19.0 & 17.2 & 11.0 & 18.9 \\
\hline
\end{tabular}

Abbreviations: ABER annual blood examination rate, SPR slide positivity rate, $A P I$ annual parasite index

${ }^{a}$ The percentage of malaria patients who were younger than 5 years of age

the rest of the Philippines in 1955; thereafter, there was a dramatic decrease in malaria morbidity. However, spraying alone was by no means a perfect tool for eliminating malaria on the islands.

\section{Evidence-based diagnoses and treatment by microscopists} KLM initiated its activities in 1999 [21]. Between 1990 and 1997, the incidence of malaria and malaria-related deaths actually increased in Palawan until 1997 and then began to decrease year by year (Fig. 1). After 2006, the total number of blood smears inspected remained at around 90,000 and the annual blood examination rate (the number of blood smears examined in a year/total population * 100) remained at around 10; however, there was a yearly decrease in the slide positivity rate (SPR) [13-16]. The number of deaths caused by malaria also began to decrease from a peak of 170 in 1997 to 9 in 2009.

In 1995, before KLM began its program of training microscopists, $76.1 \%$ of malaria diagnoses were made through symptoms and signs (Fig. 1). The proportion of evidence-based diagnoses by the microscopists increased after 1999. Consequently, in 2005, only 500 out of 16,885 patients were diagnosed based on symptoms and signs. Since 2006, all of the patients have reportedly been microscopically diagnosed.

\section{Activities of community awareness-raising for prevention}

As summarized in Fig. 2, the community awarenessraising activities of the microscopists strengthened the effective prevention practices implemented by the residents of Palawan and increased the likelihood that they would seek appropriate treatment. Community awareness-raising activities that inform residents about transmission, vector species, and the times that vector species are most active were expected to be effective in strengthening malaria prevention practices (Fig. 2, Field A) [22]. Knowledge on transmission was statistically proven to be the most important factor in this regard (pass coefficient, 4.90). To increase the likelihood that residents would seek appropriate treatment, community awareness-raising activities that sought to improve knowledge on malaria symptoms were important to make inhabitants more aware of their symptoms; this led to improved self-triage (Fig. 2, Field B) [23]. The study suggested that improving the residents' recognition of malaria symptoms and making them aware of nearby microscopists would likely be the keys to accelerating universal access to effective malaria treatment in Palawan.

These activities would be enhanced by additional follow-up interventions to improve service quality and microscopic usage ability (Fig. 2, Field C) [24]. Highcapacity microscopists could be expected to offer high service quality (active detection, diagnosis and treatment, prescription of anti-malarial, and follow-up) and to show a high level of ability in malaria microscopy (preparation and documentation, slide preparation and observation, safe handling and disposal, and knowledge on the morphology of infected red blood cells).

In addition, these activities should be intensively practiced to strengthen the preventive measures implemented by indigenous residents and people who travel to mountain areas (Fig. 2, Field A) [22, 23]. In Palawan, most of the ethno-linguistic groups live in the forests, while other residents must stay in the forest for subsistence (e.g., farming or mining). Because malaria transmission mainly occurs in the forests or adjacent areas, malaria control among those groups is the key to eliminating malaria [25-27].

\section{Overall morbidity and mortality}

The trends in the leading causes of morbidity and mortality in Palawan from 2005 to 2009 are shown in Tables 1 and 2. Prior to 2005, most of the leading causes of morbidity were infectious diseases such as malaria, respiratory infections, and urinary tract infections [14]. There were at least 170 malaria-related deaths in 1997 (Fig. 1).

From 2005, malaria was no longer a leading cause of death in the province, although the morbidity of malaria is still high (Tables 1,2), and lifestyle-related diseases, such as hypertension and cardiovascular disease, were coming to be common causes of death among Palawan residents.

Coming up in 2009, total number of confirmed malaria cases were 7606 including Plasmodium falciparum (73.1 \%), Plasmodium vivax (24.0\%), and Plasmodium malariae $(1.7 \%)$; the rest were mixed infections (data not shown). Table 3 precisely shows that there were regional differences in the annual parasite index (API). More specifically, while the human populations of the 
southern and northern regions were almost the same (334,392 and 330,879, respectively) in 2009, 2.4 times as many smears were inspected in the southern region. Furthermore, the SPR and API were, respectively, 5.3 times and 12.9 times higher than in the northern region. Regional differences were also found in the proportion of malaria infections in children younger than 5 years of age (Table 3). In the northern region, they accounted for $11.1 \%$ of malaria infections. In contrast, $19.0 \%$ of the malaria infections in the southern region were in children under 5 years of age. Thus, in the southern region, a greater percentage and a greater number of malaria infections occur in children under 5 years of age.

\section{Discussion}

Angluben et al. introduced KLM as a strategy with a focus on social mobilization in the implementation of malaria prevention and control [21]. Since the launch of KLM, microscopists had enhanced the feasibility of early diagnosis and treatment throughout the province. The achievements of KLM were reflected in the total number of malaria smears that were performed, the increase in microscopic confirmations of malaria, and the decline in clinical diagnoses between 2000 and 2006.

A novel malaria elimination strategy which aims to strengthen community awareness-raising activities by microscopists, with a focus on children under 5 years of age in the southern region of the province, indigenous people, and people who have to stay in the forest, is required. The strategy should follow a simple, effective, and affordable approach to promote the implementation of effective malaria preventive measures and to encourage residents to seek appropriate treatment. Consequently, this new strategy could accelerate the efforts to eliminate malaria in the province of Palawan, which will be adopted in the WHO's Global Technical Strategy for Malaria 2016-2030 [28], with an aim of achieving the Sustainable Development Goals by 2030 [29].

Improvements to diagnosis and treatment alone might not be sufficient to combat malaria in the southern region of the province of Palawan. Other strategies such as health promotion in schools and mother and infant medical checkups should be considered. Consideration is also needed for the geographic characteristics of the southern region which are responsible for the high rate of malaria.

As is the case in many developing nations, Palawan is facing a changing pattern of diseases. Morbidity and mortality due to infectious diseases are decreasing, while the incidence of lifestyle-related diseases or cancer is increasing. The time has come to consider whether microscopists should be given additional tasks or whether the tasks that they perform should be changed. Since Palawan has limited health facilities and human resources, task-shifting strategies that extend the mission of trained microscopists to fight these diseases should be considered.

\section{Conclusion}

The present study proposed a new strategy to enhance activities by microscopists to raise malaria awareness in their respective communities. These activities are expected to strengthen the preventive measures implemented by the residents and to drive more people to seek appropriate treatment. Consequently, this new strategy could accelerate the efforts to eliminate malaria in the province of Palawan, the Philippines.

\section{Ethics approval and consent to participate}

The present study was approved by the Research Ethics Committee of the University of Tokyo (no. 3001) and upheld by the Provincial Health Office of Palawan. Before the epidemiological data collections, we asked informants to sign a consent form after being informed about the study purpose and told them that they could withdraw from the study during the data collection or even afterwards.

\section{Abbreviations \\ ABER: annual blood examination rate (number of blood smears examined in a year/total population * 100); API: annual parasite index (number of malaria patients per year/total population * 1000); BHWs: barangay (village) health workers; CHWs: community health workers; DDT: dichloro-diphenyl- trichloroethane; KLM: Kilusan Ligtas Malaria (Tagalog: Movement Against Malaria); SPR: slide positivity rate (number of positive slides/total blood smears * 100); WHO: World Health Organization.}

\section{Competing interests}

The authors declare that they have no competing interests.

\section{Authors' contributions}

ELAM-T and SK designed the present study, conducted the fieldwork, collected the data on the province, analyzed the data, and wrote the present paper. Both authors read and approved the final manuscript.

\section{Acknowledgements}

The authors were grateful to the Provincial Health Office of Palawan, the Municipal Health Offices, and the health centers of Palawan for their warm support. The authors would also like to thank Dr. Pilarita Tongol-Rivera, Ms. Elena A. Villacorte, Mr. Ray U. Angluben, and Dr. Masamine Jimba for their professional advice and encouragements.

\section{Funding}

The present study was supported by grants-in-aid from the Japanese Ministry of Health, Labour and Welfare (H21-Chikyukibo-Ippan-006) and the National Center for Global Health and Medicine (25A2). The funders had no role in the study design, data collection and analysis, decision to publish, or the preparation of this manuscript.

Received: 13 November 2015 Accepted: 29 December 2015 Published online: 10 April 2016

\section{References}

1. WHO | World Malaria Report 2014. 2014. http://www.who.int/malaria/ publications/world_malaria_report_2014/report/en/. Accessed 26 Nov 2015. 2. White NJ, Pukrittayakamee S, Hien TT, Faiz MA, Mokuolu OA, et al. Malaria. Lancet. 2014;383(9918):723-35. doi:10.1016/S0140-6736(13)60024-0. 
3. Alonso PL, Brown G, Arevalo-Herrera M, Binka F, Chitnis C, et al. A research agenda to underpin malaria eradication. PLoS Med. 2011;8(1):e10000406 doi:10.1371/journal.pmed.1000406.

4. Feachem RG, Phillips AA, Targett GA, Snow RW. Call to action: priorities for malaria elimination. Lancet. 2010;376(9752):1517-21. doi:10.1016/ S0140-6736(10)61500-0.

5. World Bank. World Development Report 2004: making services work for poor people. 2004. https://openknowledge.worldbank.org/handle/10986/ 5986. Accessed 26 Nov 2015.

6. Mathauer I, Imhoff I. Health worker motivation in Africa: the role of non-financial incentives and human resource management tools. Hum Resour Health. 2006:4:24. doi:10.1186/1478-4491-4-24

7. Moore SJ, Min X, Hill N, Jones C, Zaixing Z, et al. Border malaria in China: knowledge and use of personal protection by minority populations and implications for malaria control: a questionnaire-based survey. BMC Public Health. 2008;8:344. doi:10.1186/1471-2458-8-344

8. Khamsiriwatchara A, Wangroongsarb P, Thwing J, Eliades J, Satimai W, et al. Respondent-driven sampling on the Thailand-Cambodia border. I. Can malaria cases be contained in mobile migrant workers? Malar J. 2011;10:120. doi:10.1186/1475-2875-10-120.

9. Christopher JB, Le May A, Lewin S, Ross DA. Thirty years after Alma-Ata: a systematic review of the impact of community health workers delivering curative interventions against malaria, pneumonia and diarrhoea on child mortality and morbidity in sub-Saharan Africa. Hum Resour Health. 2011;9: 27. doi:10.1186/1478-4491-9-27.

10. Smith Paintain L, Willey B, Kedenge S, Sharkey A, Kim J, et al. Community health workers and stand-alone or integrated case management of malaria: a systematic literature review. Am J Trop Med Hyg. 2014;91(3):461-70. doi: 10.4269/ajtmh.14-0094.

11. Lehmann U, Sanders D. Community health workers: what do we know about them? 2007. http://www.who.int/hrh/documents/community_health_ workers.pdf. Accessed 26 Nov 2015

12. Lariosa TR. The role of community health workers in malaria control in the Philippines. Southeast Asian J Trop Med Public Health. 1992;23 Suppl 1:30-5.

13. Provincial Health Office of Palawan. Provincial health report, 1995. Palawan, Republic of the Philippines: Provincial Health Office of Palawan; 1995.

14. Provincial Health Office of Palawan. Provincial health report, 2000. Palawan, Republic of the Philippines: Provincial Health Office of Palawan; 2000.

15. Provincial Health Office of Palawan. Provincial health report, 2005. Palawan, Republic of the Philippines: Provincial Health Office of Palawan; 2005.

16. Provincial Health Office of Palawan. Provincial health report, 2010. Palawan, Republic of the Philippines: Provincial Health Office of Palawan; 2010.

17. National Statistical Coordination Board. Population of the Philippines census years 1799 to 2010. Manila, Republic of the Philippines: National Statistical Coordination Board; 2012.

18. Tongol-Rivera P. Milestones in the history of malaria research and its control in the Philippines. In: Kano S, Tongol-Rivera P, editors. Asian parasitology Chiba, Japan: The Federation of Asian Parasitologists; 2005. p. 135-66.

19. The Rockefeller Foundation. The Rockefeller Foundation Annual Report. New York: The Rockfeller Foundation; 1931.

20. Trigg PI, Kondrachine AV. Commentary: malaria control in the 1990s. Bull World Health Organ. 1998;76:11-6.

21. Angluben RU, Trudeau MR, Kano S, Tongol-Rivera P. Kilusan Ligtas Malaria: advancing social mobilization towards sustainable malaria control in the province of Palawan, the Philippines. Trop Med Health. 2008;36(1):45-9. doi: 10.2149/tmh.36.45

22. Matsumoto-Takahashi EL, Tongol-Rivera P, Villacorte EA, Angluben RU, Yasuoka J, et al. Determining the impact of community awareness-raising activities on the prevention of malaria transmission in Palawan, the Philippines. Parasitol Int. 2014;63(3):519-26. doi:10.1016/j.parint.2014.01.008.

23. Matsumoto-Takahashi EL, Tongol-Rivera P, Villacorte EA, Angluben RU, Jimba $\mathrm{M}$, et al. Patient knowledge on malaria symptoms is a key to promoting universal access of patients to effective malaria treatment in Palawan, the Philippines. PLoS One. 2015;10(6):e0127858. doi:10.1371/ journal.pone.0127858.

24. Matsumoto-Takahashi EL, Tongol-Rivera P, Villacorte EA, Angluben RU, Yasuoka J, et al. Determining the active role of microscopists in community awareness-raising activities for malaria prevention: a crosssectional study in Palawan, the Philippines. Malar J. 2013:12:384 doi:10.1186/1475-2875-12-38
25. Incardona S, Vong S, Chiv L, Lim P, Nhem S, et al. Large-scale malaria survey in Cambodia: novel insights on species distribution and risk factors. Malar J. 2007;6:37.

26. Singh N, Mishra AK, Shukla MM, Chand SK. Forest malaria in Chhindwara, Madhya Pradesh, central India: a case study in a tribal community. Am J Trop Med Hyg. 2003;68:602-7.

27. Dysoley L, Kaneko A, Eto H, Mita T, Socheat D, et al. Changing patterns of forest malaria among the mobile adult male population in Chumkiri District, Cambodia. Acta Trop. 2008;106(3):207-12. doi:10.1016/j.actatropica.2007.01.007.

28. WHO. Global Technical Strategy for Malaria 2016-2030. 2015. http://www. who.int/malaria/areas/global_technical_strategy/en/. Accessed 26 Nov 2015.

29. United Nations Sustainable Development Knowledge Platform. Transforming our world: the 2030 agenda for sustainable development 2015. https://sustainabledevelopment.un.org/post2015/ transformingourworld. Accessed 26 Nov 2015.

\section{Submit your next manuscript to BioMed Central and we will help you at every step:}

- We accept pre-submission inquiries

- Our selector tool helps you to find the most relevant journal

- We provide round the clock customer support

- Convenient online submission

- Thorough peer review

- Inclusion in PubMed and all major indexing services

- Maximum visibility for your research

Submit your manuscript at www.biomedcentral.com/submit
) Biomed Central 